- 2014, which sees companies bid for funding for emissions-reduction programmes. From 1 July, firms will be forced to buy carbon credits if they exceed a ceiling on carbon emissions.

But falling demand for electricity means that is unlikely to happen to electricity generators, says Dylan McConnell, a research fellow at the Melbourne Energy Institute at the University of Melbourne, because the ceiling is set at a high point for emissions that was reached between 2009 and 2014. He says that the government's policies are "definitely not adequate" to achieve its targets of cutting emissions to $26-28 \%$ below 2005 levels by 2030. A spokesperson for environment minister Greg Hunt disagreed, saying that the government's policies put it on track to meet its 2030 targets.

The Labor opposition, which under leader Bill Shorten has a slight edge in opinion polls, is more ambitious: it has pledged to reduce emissions by $45 \%$ below 2005 levels by 2030 , and to be carbon neutral by 2050 . Labor would also introduce an emissions-trading scheme for electricity producers. "Labor's policies are stronger with a clearer pathway to credibility than the coalition's, but much detail remains to be sorted," says Connor. For example, it is not clear where the threshold on emissions intensity would be set.

Climate analysts think that in practice, the

two approaches could end up operating in a similar way - with the coalition's pay-tocut-emissions plan morphing into an emissions-trading scheme similar to the Labor

"Australia has one of the lowest emissionsreduction targets." proposal. "When you look at the policies, unless you're a policy nerd, there's not really much difference," says Tony Wood, head of the energy programme at the Grattan Institute, a think tank in Melbourne. Hunt's spokesperson rebuffed any comparison, saying that the government was not running an emissionstrading scheme.

With warming oceans causing extensive damage to Australia's iconic Great Barrier Reef, rival politicians are keen to be seen as promising action. On 30 May, Shorten pledged Aus $\$ 377$ million (US\$279 million) in new funding to improve the health of the reef, if he is elected. Turnbull then announced that his government would use up to Aus $\$ 1$ billion from an existing clean-energy programme to support the reef's health through projects to improve water quality, reduce emissions and provide clean energy. But marine biologist Terry Hughes, director of the ARC Centre of Excellence for Coral Reef Studies at James Cook
University in Townsville - who has made headlines with his reef-bleaching studies (see also Nature http://doi.org/bj45; 2016) — says that the money will make little difference because it won't tackle the fact that global warming is the greatest threat to the reef. "Australia has one of the lowest emissions-reduction targets of any developed country and the highest per capita emissions. Those are the two areas the government should be addressing," says Hughes.

The government also refused to intervene when cuts to climate-change programmes at the national science agency, the Commonwealth Scientific and Industrial Research Organisation (CSIRO), were revealed earlier this year. The opposition has committed to an independent review of the agency and, on 12 June, promised CSIRO Aus $\$ 250$ million extra as part of a package to fund various science programmes, if the party is elected.

Jotzo and Wood see the quieter consensus for action on carbon emissions as a relief after a decade of contentious climate politics. Those years saw a carbon 'tax' introduced by Labor's Julia Gillard in 2012, and then dismantled by a conservative coalition led by Tony Abbott in 2014. "There is an opportunity for bipartisanship, which is part of the reason why the toxicity of the debate in this election hasn't been so strong," says Wood. .

\title{
Giant telescope rattles rural South African community
}

\section{Struggle over Square Kilometre Array highlights balancing act that scientists face.}

\section{BY SARAH WILD, NORTHERN CAPE PROVINCE}

"M ove it away! We don't want it!" a farmer shouted at a crowded meeting in Carnarvon, a small town in the semi-arid, sparsely populated Northern Cape, one of South Africa's poorer provinces. He was talking about what will be the largest radio telescope in the world, the international Square Kilometre Array (SKA), a portion of which is due to be built nearby.

Representatives from SKA South Africa, an organization of scientists, engineers and technocrats, were attending the meeting of farmers in May, in an attempt to respond to rising criticism of the project from local people. "It's fine to be part of the international community, but how is it helping this community?" came a faceless call from the other side of the meeting hall.

In 2012, the SKA's coordinating organization decided that it would divide its thousands of dishes and many more antennas, whose combined 'collecting area' for radio waves will span approximately one square kilometre, between Australia and South Africa. The site in the Northern Cape will include 197 dishes, and

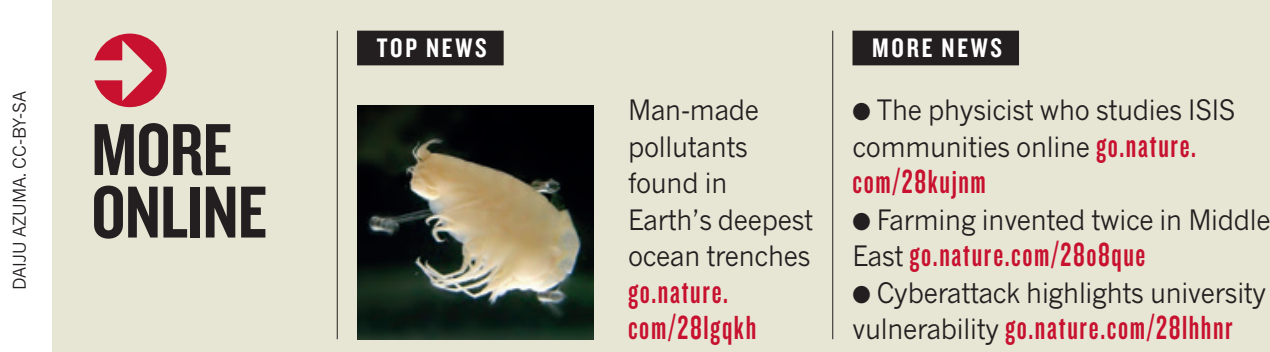

\section{NATURE PODCAST}

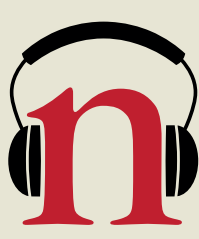

Transmissible cancer; the hadron menagerie; and the latest gravitational-wave result nature.com/ nature/podcast 


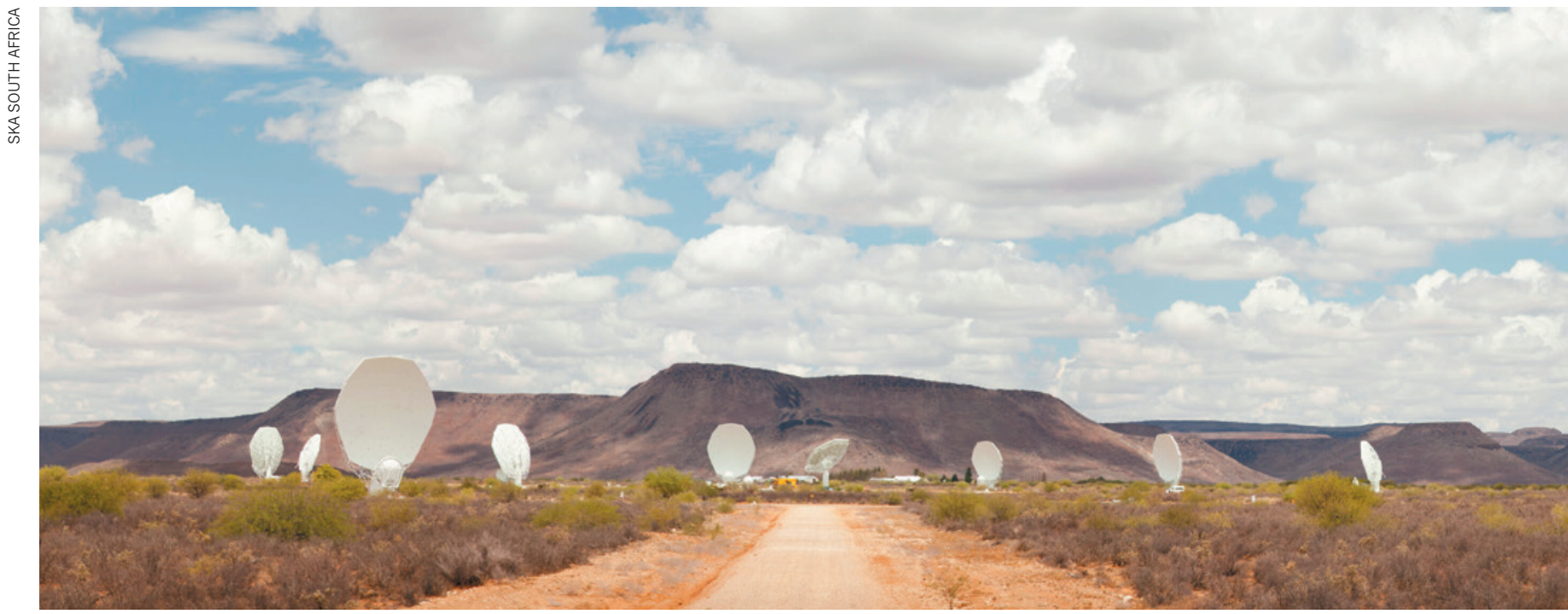

The MeerKAT telescope under construction in South Africa's Northern Cape will form part of the world's largest radio telescope.

form part of the project's first phase, SKA1. The 64-dish MeerKAT telescope, which will be part of SKA1, is already being built. The rest of the dishes will be added from 2018.

Last year, opposition to the Thirty Meter Telescope on Mauna Kea, Hawaii, prompted the state's supreme court to invalidate the telescope's construction permit. Opposition to the SKA is unlikely to derail the project because legislation protects most of the Northern Cape for astronomy. But SKA South Africa officials say that they need community buy-in if the project is to be sustainable over its 50-year life.

The struggle that is playing out in the Northern Cape illustrates the balancing act that scientists who lead gigantic projects must pull off - to highlight the benefits that the project will bring to an area without overinflating expectations.

When SKA South Africa proposed the SKA project to the Northern Cape community, starting with the MeerKAT telescope in 2008, it said that the project would lead to local economic development, create jobs and improve opportunities for children through education and science. But the organization never quantified these objectives - and now its director, Rob Adam, is struggling to manage the expectations of the poorest members of the Northern Cape, who are largely 'coloured' people, a recognized racial classification in South Africa.

SKA South Africa has already come good on some of its promises. It now employs a high-school maths and science teacher for Carnarvon, for example, and is paying for five coloured students at Carnarvon high school to attend university as part of a pan-African bursary programme that it runs. But members of the coloured community complain that such resources haven't materialized across the board - not all the towns in the area have gained a high-school teacher, for example.

And although a small influx of scientists,

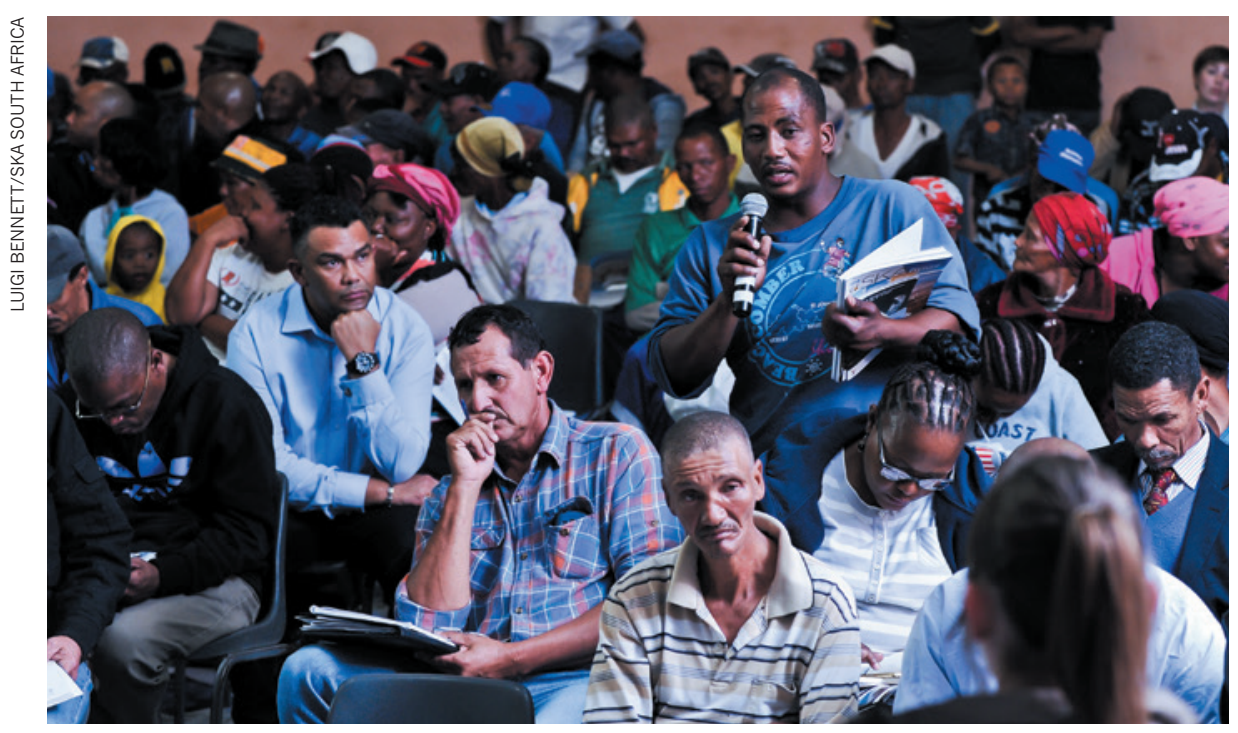

Northern Cape residents voice discontent with construction of the Square Kilometre Array.

engineers and contractors has to some extent improved the economies of the province's towns, the communities are not yet satisfied. "What's in it for us?" asked one resident at a meeting in the Northern Cape town of Brandvlei in May.

Adam says that the community's expectations have risen beyond what the SKA can provide. "You must understand, we are not the government, the education department and the police, all rolled into one," he told the crowd in Brandvlei.

The problem is different for members of the richer, mainly white, sheep-farming community of the Northern Cape, who are concerned about SKA South Africa's land acquisition.

According to the Astronomy Geographic Advantage Act, which was passed in 2007, the government has the right to acquire land for the project within a designated 'core' area if negotiations fail, and if the land is required for the SKA and the organization has offered a fair price.

In 2008, the government bought Losberg farm, the site of the MeerKAT telescope. What is riling this community is that SKA South Africa is now eyeing 36 other farms - which comprise about 118,000 hectares - to accommodate the further 133 dishes that make up SKA1.

Many farmers say that the loss of their farms will destroy the local, agriculture-based economy, and that they are being forced to sell. Although the amount of land needed for the SKA is now agreed, the farmers are also suspicious about the scope of the project. "They don't believe things will stop here," says Henning Myburgh, general manager of farmers' organization Agri Northern Cape in Kimberley.

The spectre of Zimbabwe-style land expropriation, in which the government took land from white farmers without compensation, is also present. "It's a land grab, one way or the 
> other, be it for SKA or something else," says Eric Torr, a former resident of the province who owns a local aviation company.

Expropriation would be a last resort, say SKA South Africa officials. "It's not in the best interests of the SKA to do that because we have to live in this community," says Alice Pienaar-Marais, who is in charge of the landacquisition process. She is confident that SKA
South Africa will acquire the 36 farms by the end of next year, in time for SKA1 construction in 2018

SKA Australia, meanwhile, "could be doing more" with respect to community engagement, project director David Luchetti told Nature.

The Australian SKA Pathfinder telescope, which is currently being commissioned, is to be built on an area that traditionally belongs to the Wajarri Yamatji tribe. Following the 2009 Indigenous Land Use Agreement, which was negotiated between the government and the indigenous group, the tribe has received benefits worth more than Aus $\$ 18.1$ million (US\$13.5 million) in exchange for the use of the land for radioastronomy.

But the agreement needs to be renegotiated for the SKA before construction starts.

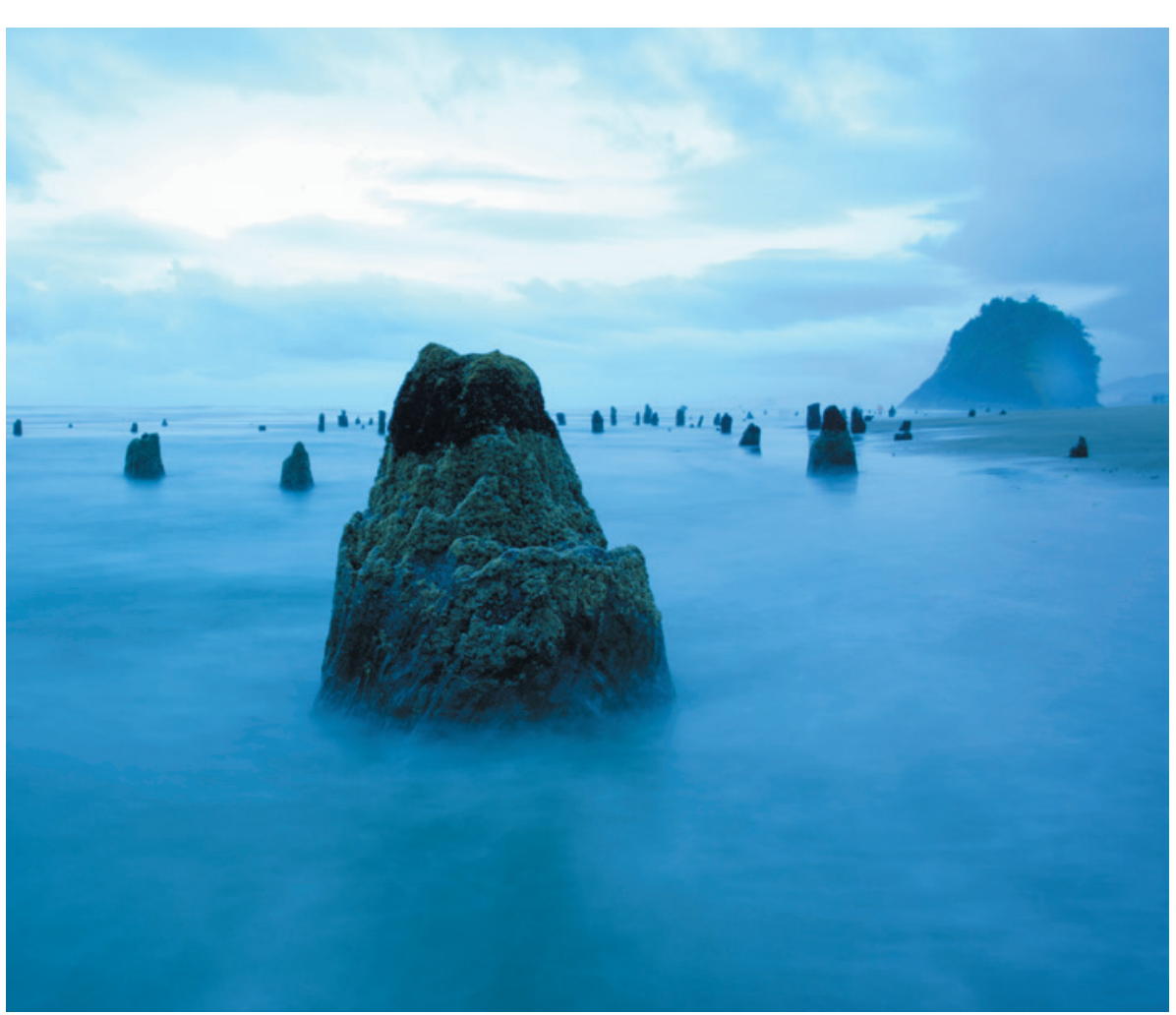

An earthquake-triggered tsunami is thought to have drowned this Pacific Northwest forest 2,000 years ago.

\section{SEISMOLOGY}

\section{Canada builds quake warning system}

\section{Undersea instruments will monitor the Cascadia fault zone.}

\section{BY NICOLA JONES}

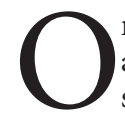
n 15 June, Canada broke ground on an offshore earthquake early-warning system. Sea-floor sensors will monitor the Cascadia subduction zone off British Columbia to provide crucial seconds of warning if the 'big one' hits. Putting sensors so close to the fault should give the Canadian system an edge over a more developed sister project in the United States.

To produce early warnings of quakes, scientists rely on a network of seismometers and accelerometers to detect the tremor's first, non-destructive primary $(\mathrm{P})$ waves. Those waves travel faster than the destructive secondary (S) waves, and so hit cities seconds to minutes earlier. The closer that detectors are to the source of an earthquake, the more warning they can provide. That time can be used to stop high-speed trains, shut down nuclear reactors and tell the general population to brace for shaking. But with offshore faults, getting close to the action means putting sensors under water, which is very expensive.

Japan pioneered earthquake early warnings. The country has had a system to stop bullet trains since the 1960s, and public warnings have been issued since 2007. During the magnitude- 9 Tohoku earthquake of March 2011, residents of Sendai, the major city nearest to the epicentre, got 15 seconds of warning; Tokyo got more than a minute. Japan added data from an array of undersea seismometers to its earthquake earlywarning system in August 2011, and a second phase of that project was completed in March, more than doubling the number of offshore detectors to 50. Now, the country is working on an ambitious 150-station network called S-net. Connected by 5,700 kilometres of cable, it could provide up to an extra 30 seconds of warning for a large offshore quake.

The United States and Canada have lagged far behind Japan, despite the fact that the Cascadia subduction zone off North America's west coast is expected to one day produce a catastrophic 'megathrust' quake similar to the Tohoku one.

By the end of June, the research non-profit group Ocean Networks Canada (ONC) in Victoria plans to have installed three accelerometers on its NEPTUNE sea-floor observatory, which consists of more than 840 kilometres of ocean-bottom cable looped out past the Cascadia fault (see 'Quake watch'). "I took this job and asked, 'Why aren't we doing earthquake early warning?" says ONC president Kate Moran, who joined the organization in 2011 as director of NEPTUNE.

The network already has a handful of seismometers, but these send data back in packets instead of instantaneously, and the information is subject to censorship by the navy. As such, Moran says, they are illsuited for an early-warning system. The new accelerometers, which have a simpler data stream designed to circumvent these issues, were made possible by a Can $\$ 5$-million (US\$3.9-million) grant from the British Columbia government in February.

The team is also hoping to install a tiltmeter down a 300-metre borehole, to detect slow, almost imperceptible movement of the tectonic plates at the fault. Clusters of such slow-slip events occurred before the 2011 Japan quake, and detecting them might help seismologists to track the strain that is building on the fault.

Moran anticipates that within 5 years, the ONC will have 40 accelerometers on- and 


\section{NEWS INFOCUS}

\section{CORRECTION}

The News story 'Canada builds quake warning system' (Nature 534, 446-447;

2016) incorrectly stated that the warning system being developed by Ocean Networks Canada would be the first in Canada. 